\title{
AS APROPRIAÇÕES DO SABER HISTÓRICO POR MEIO DO LIVRO DIDÁTICO DE HISTÓRIA DA REDE SALESIANA DE ESCOLA
}

\author{
THE APPROPRIATION OF KNOWLEDGE THROUGH SALESIAN SCHOOLS HISTORY \\ TEXTBOOKS ${ }^{1}$
}

Geane Kantovitz ${ }^{2}$

\begin{abstract}
RESUMO: O artigo versa sobre o resultado da pesquisa de mestrado a qual procurou discutir as apropriações dos saberes históricos, no que concerne à temporalidade histórica, e a relação que os alunos estabelecem com a sua vida fora do contexto escolar. Utiliza-se o livro didático de História do ensino médio como propulsor e norteador das análises. Considera-se como os alunos compreendem a História pela leitura do livro didático e como estabelecem uma relação da disciplina de História com a vida. Ou seja, como os alunos se orientam no tempo pela disciplina de História. Nesse texto aborda-se, principalmente, a importância da disciplina de História para os alunos da terceira série do ensino médio da Rede Salesiana de Escolas (RSE) para a formação do pensamento histórico. Utiliza-se como percurso analítico as contribuições de Koselleck (2006), de Le Goff (2003), Hobsbawm (1998) e de Rüsen (2010). Em relação ao percurso metodológico foram utilizadas respostas objetivas e discursivas de 173 alunos da terceira série do ensino médio, de quatro professores de História e dos autores da coleção de livros da RSE. Mediante às análises, conclui-se que há um distanciamento entre os pressupostos do livro didático e a apropriação dos conteúdos por parte dos alunos da terceira série do ensino médio; evidencia-se também uma significativa importância do professor na construção de uma representação de credibilidade do livro e sua influência na construção da consciência histórica, visto que o material é considerado, tanto pelos professores quanto pelos alunos, excessivamente teórico. Por fim, percebe-se que os alunos pesquisados estruturam seu pensamento histórico numa perspectiva de causa e consequência linear dos acontecimentos. Ou melhor, compactuam com uma visão unilateral dos fatos históricos.
\end{abstract}

Palavras-chave: Ensino de História. Livro didático. Temporalidade histórica.

\footnotetext{
${ }^{1}$ Pesquisa referente ao mestrado financiada pela Cnpq.

2 Pesquisadora na área da Educação e bolsista CAPES-FAPESC. Doutoranda em Educação da UFSC.
} 
ABSTRACT: This paper discusses the result of the master's research, which sought to discuss the appropriation of historical knowledge regarding the historical temporality, and the relationship that students have with their lives outside school. The high school history textbook is used as a driving force guiding the analyzes. It is considered as the students understand the history by reading the textbook, and how to establish a relationship of the discipline of history to life. In other words, how students orient themselves in time for the discipline of history. In this text, it discusses mainly, the importance of the discipline of history to students of the third year of high school of the Salesian Schools, for the formation of historical thought. It uses as analytical course, contributions from Koselleck (2006), Le Goff (2003), Hobsbawm (1998) and Rüsen (2010). It was used, regarding the methodological approach, objective and discursive responses of 173 students of the third year of high school, of four History teachers, and of the authors of the collection of books of the Salesian schools.

Keywords: History teaching. Textbook. Historical temporality. 


\section{Introdução}

O artigo é fragmento da pesquisa de mestrado desenvolvida junto ao Programa de Pós-Graduação em Educação, na Universidade Federal de Santa Catarina (UFSC) intitulada "O livro didático de História da Rede Salesiana de Escolas em Santa Catarina: desafios na formação do pensamento Histórico". No cotejo dos resultados, discute-se aqui as apropriações dos saberes históricos e a relação que os alunos estabelecem com a sua vida fora do contexto escolar. Em outras palavras, procura-se saber como os alunos se apropriam da História ensinada nos livros didáticos e como compreendem o movimento da História a partir do tempo histórico numa perspectiva de presente, passado e futuro, na acepção de Koselleck (2006) ao se referir em "experiência" e "expectativa". Embora não tratar especificamente sobre o Ensino de História, a obra Futuro Passado de Reinhart Koselleck contribuiu significativamente para as discussões acerca da temporalidade histórica utilizando os conceitos de "espaço de experiência" e "horizonte de expectativa".

Por um lado, o autor demonstra as conexões existentes entre o pensamento político/social e os sujeitos, por outro, como se dá o amálgama entre as consciências históricas que expressam o quanto o conhecimento histórico pode tematizar as condições de possibilidade de histórias e a própria existência humana (KOSELLECK, 2006). Segundo Koselleck (2006, p. 306- 307), "todas as histórias foram constituídas pelas experiências vividas e pelas expectativas das pessoas que atuam ou que sofrem" ou, ainda, "não há expectativa sem experiência, não há experiência sem expectativa".

Nessa perspectiva, procura-se compreender como os alunos se apropriam dos conteúdos históricos por intermédio do livro didático de História da Rede Salesiana de Escolas (RSE) para orientar a sua vida pelo passado, ou seja, pela experiência.

Considerando a densidade do conceito de temporalidade histórica, opta-se por utilizar outros autores, como Hobsbawm (1998), Le Goff (2003) e Rüsen (2010), os quais também contribuem no percurso analítico percorrido, tal como Koselleck (2006). 
No que se refere à metodologia, foram entrevistados 173 alunos da $3^{a}$ série do ensino médio e quatro professores, os quais eram integrantes de cinco escolas da Rede Salesiana (RSE) do estado de Santa Catarina. ${ }^{3}$ Os três autores do livro de História, também participaram da pesquisa contribuindo com suas entrevistas e considerações sobre a produção e utilização do material.

\section{A RSE e a coleção de livros didáticos de História do ensino médio}

De acordo com Bisewski (2008), foi a partir de 2002 que surgiu oficialmente a Rede Salesiana de Escolas. ${ }^{4}$ Assim, desde que iniciou a Proposta Pedagógica, a qual foi concretizada em 2005, passou a implantar o livro didático não somente como apoio metodológico ao professor, mas sim, como principal instrumento de concretização da unidade pedagógica e metodológica do processo de ensino e aprendizagem em todas as escolas salesianas do Brasil.

O livro didático é considerado, pela RSE, o instrumento metodológico mais importante a ser utilizado pelos professores, sendo entendido como integrante do processo de ensino e aprendizagem na formação do pensamento histórico e como principal componente da cultura material escolar, objetivando concretizar a Proposta Pedagógica para as escolas da Rede de todo o Brasil.

É fundamental destacar que, desde a elaboração, produção e utilização do livro didático no cotidiano escolar, um conjunto de fatores deve ser considerado, como, por exemplo, a produção e circulação de ideias prescritas no conteúdo a ser ensinado, bem como os usos e apropriações do livro em questão. No entanto, o que se pretende no presente texto, é observar de que maneira o livro didático de História do ensino médio, pode contribuir na compreensão da temporalidade histórica e como orientar a sua vida pelo passado, ou seja, pela experiência.

A coleção de História do ensino médio da RSE não é uma coleção escolhida pelo professor, conforme ocorre com os livros didáticos avaliados pelo Programa

\footnotetext{
${ }^{3}$ A escolha pelos alunos da terceira série do ensino médio para contribuir na pesquisa e responder ao questionário justifica-se por ser a última etapa de implantação do livro didático, pois a maioria deles já utilizava o livro desde o início do Projeto Pedagógico da RSE.

${ }^{4}$ As escolas da RSE no Brasil estão organizadas em seis polos: Manaus (AM), Recife (PE), Campo Grande (MS), Belo Horizonte (MG), São Paulo (SP) e Porto Alegre (RS). As cinco escolas de Santa Catarina fazem parte do polo de Porto Alegre. As escolas da Rede são particulares e de cunho religioso católico em virtude de pertencerem a congregações religiosas salesianas.
} 
Nacional do Livro Didático (PNLD), do Ministério da Educação e Cultura (MEC). Ela é uma coleção implantada nas escolas da Rede a partir do ano 2005. Salienta-se que o professor que utiliza os livros participa do processo de avaliação e não da escolha. Assim, o processo de aceitação do livro por parte dos professores, direção, coordenação pedagógica, alunos e pais é considerado fundamental, pela Rede, no processo de implantação da proposta pedagógica nas escolas salesianas.

Ao considerar o livro didático como principal instrumento de trabalho do professor, compreende-se tal objeto pedagógico como importante organismo da formação da consciência histórica. Porém, os diferentes olhares sobre um único objeto são variáveis, ou seja, podem ser representados e apropriados de distintas formas, tanto pelos professores quanto pelos alunos que o utilizam. Sendo assim, torna-se importante analisar como o livro didático pode contribuir na compreensão da temporalidade histórica e suas multiplicidades.

\section{Ensino de História e temporalidade histórica}

No Brasil, o ensino de História no fim do século $X X$, especificamente, a partir da década de 1980, adquire novos olhares e novas perspectivas, pois até então era voltado para a formação cívica, sendo seu principal objetivo legitimar o papel do Estado Nacional na formação do cidadão patriota e devoto aos heróis nacionais despertando o sentimento de orgulho de a ele pertencer.

Nessa dimensão, a prática do ensino de História nas escolas era simples: limitava-se a narração de fatos históricos selecionados por classes sociais e políticas dirigentes, caracterizados por momentos considerados importantes na formação da nação, baseado nos relatos de "grandes feitos" e de "grandes homens".

Ao se referir a trajetória do ensino de História num âmbito mais geral, Laville (1999, p. 126), assim destaca:

Essa maneira de ensinar história foi se tornando menos necessária à medida que as nações foram percebendo que estavam bem assentadas e cessaram de temer por sua própria existência. Nos 
países ocidentais, o fim da Segunda Guerra Mundial foi o marco de uma etapa importante. [...] A idéia de 'cidadão participante' começou a substituir a de 'cidadão súdito'. O ensino de História não deixou de ganhar com isso. Ao contrário, viu a função de educação para a cidadania democrática substituir sua função anterior de instrução nacional.

No Brasil, segundo Nadai (2009, p. 30), durante muito tempo a História se apresentou "como uma das disciplinas fundamentais no processo de formação de uma identidade comum - o cidadão nacional - destinado a continuar a obra de organização da nação brasileira". Porém, o movimento de mudança de perspectiva do ensino de História, no país, é mais recente. Nas palavras de Nadai (2009, p. 31), essa mudança mais lenta no Brasil deu-se em consequência das "modificações intrínsecas à constituição do próprio discurso histórico e de outro pelas modificações que alteram a feição e a natureza da escola secundária".

Fonseca (2003, p. 56) destaca que no Brasil essa mudança de olhar para a escrita da História desenvolve-se a partir das décadas de 1980 e 1990 . A autora salienta que a partir desse período o "livro didático deixou de se dedicar quase que exclusivamente aos fatos da política institucional e alargou o campo do conhecimento histórico ensinado nas escolas". Desse modo, percebe-se nas últimas décadas uma tentativa de reestruturar os conteúdos históricos numa visão mais crítica, que possibilite ao aluno um pensar histórico voltado a problematização da História.

Porém, o que se constatou na pesquisa é que as permanências sobre o ensino de História ainda estão muito voltadas para a representação da História como uma disciplina que estuda somente o passado, ou seja, para alguns alunos, o historiador (ou professor de História) é um profissional que estuda, pesquisa o passado e o transmite. Um dos alunos entrevistado diz que a História é importante para "compreender melhor o passado, os acontecimentos ocorridos". Outro aluno explica:

Pois é muito importante para nós termos um total conhecimento do passado, claro que não vamos ter total conhecimento, mas ir buscando cada vez mais, para sabermos diversas coisas, como, por exemplo, as histórias do nosso país e de outros países, o motivo de alguns acontecimentos, e até mesmo acontecimentos que ficaram marcados, e assim vai. (Resposta do aluno, 2010). 
Esses relatos representam uma pequena parcela dos jovens que hoje estão concluindo o ensino médio na RSE. Todavia, como constatado na pesquisa, são representações ainda muito presentes entre os jovens, principalmente naqueles que estudam em escolas particulares visando ao vestibular e ao mercado de trabalho.

Em relação à compreensão do passado, questiona-se primeiramente o que é o passado. Hobsbawm (1998, p. 22) diz que:

\begin{abstract}
todo ser humano tem consciência do passado (definido como o período imediatamente anterior aos eventos registrados na memória de um indivíduo) em virtude de viver com pessoas mais velhas. Provavelmente todas as sociedades que interessam aos historiadores tenham um passado, pois mesmo as colônias mais inovadoras são povoadas por pessoas oriundas de alguma sociedade que já conta com uma longa história. Ser membro de uma comunidade humana é situar-se em relação ao seu passado (ou da comunidade), ainda que apenas para rejeitá-lo. O passado é, portanto, uma dimensão permanente da consciência humana, um componente inevitável das instituições, valores e outros padrões da sociedade humana. O problema para os historiadores é analisar a natureza desse 'sentido do passado' na sociedade e localizar suas mudanças e transformações.
\end{abstract}

Bloch (2001, p. 75) também aborda uma concepção de passado dizendo: "O passado é, por definição, um dado que nada mais modificará. Mas o conhecimento do passado é uma coisa em progresso, que incessantemente se transforma e aperfeiçoa".

Assim como Reinhart Koselleck, Marc Bloch e Eric Hobsbawm não se referem especificamente ao Ensino de História e aos usos do livro didático. No entanto, os autores contribuem nas análises historiográficas sobre a temporalidade histórica. Ou melhor, tanto Bloch (2001) quanto Hobsbawm (1998), abordam perspectivas pertinentes em relação à compreensão do passado, presente e futuro. Nesse sentido, diante das suas concepções, percebese, no relato de alguns alunos, um ponto de vista sobre a História na qual eles não a compreendem como uma ligação com o seu presente, ou com a sua história de vida. Entendem o passado como algo estático, que está guardado e sempre à disposição para ser relatado e usado por profissionais que se 
interessam por ele e assim não tendo sentido significativo, concepção que vai no sentido contrário das acepções dos autores mencionados.

Nessa linha de pensamento, remete-se aos argumentos de Rüsen (2010) no que se refere ao livro didático de História. O autor alemão dedicou parte de suas pesquisas, referentes ao Ensino de História, abordando a utilidade do livro didático para o ensino prático para além da sala de aula. Jörn Rüsen ao refletir sobre o livro didático chega a discorrer sobre como deveria ser o livro didático ideal que estaria em consonância com as orientações na vida prática dos sujeitos, elencando assim, alguns elementos que pudessem contribuir efetivamente com o aprendizado histórico (RÜSEN, 2010). Segundo o autor, "o livro de história é o guia mais importante da aula de história. Por esse motivo, deve-se partir da pergunta do que se pretende conseguir através da aula de história" (RÜSEN, 2010, p. 112). Portanto, nos relatos descritos pelos alunos, em relação ao livro de História e a importância da História, verifica-se que o livro didático é representado como um instrumento que contém fatos ocorridos no passado e que não possuem relação com a vida deles.

Outra fala que se evidencia é quando o aluno se refere à importância do livro didático da seguinte maneira: "Sim, pois vai ser por meio dele que vou conseguir explicar um pouco mais da história para as pessoas que não tiveram acesso a história, que não conhecem o que ocorreu no passado". Ou seja, o aluno tem consciência da importância do livro didático, porém não consegue relacionar a escrita da História com o seu cotidiano.

Para Koselleck (2006, p. 308), a História só pode ser composta "a partir de dois modos de ser, o da recordação e o da esperança" e que "esperança e recordação, ou mais genericamente, expectativa e experiência [...] são constitutivas, ao mesmo tempo, da história e de seu conhecimento, e certamente o fazem mostrando e produzindo a relação interna entre passado e futuro, hoje e amanhã". Nesse sentido, entre a experiência e expectativa, o autor argumenta que há a constituição do tempo histórico. Ou melhor, é na relação entre o passado - experiência - e futuro - expectativa - é possível afirmar, na acepção de Koselleck (2006), que surge uma relação com o tempo que caracteriza-se como tempo histórico. Diante desses argumentos, infere-se que alguns jovens, apesar da mudança de enfoque da historiografia e das discussões sobre as 
temporalidades históricas, desvinculam a relação entre o passado e o futuro, quer dizer, não vinculam a experiência do passado com a expectativa com o futuro, dificultando assim, a compreensão do tempo histórico.

Nessa perspectiva, os alunos participam da produção do sentido de um texto conforme a sua posição e seus interesses, ou seja, considerando que eles estão interessados em passar no vestibular e ter bons indicadores no ENEM, muitos deles produzem sentidos somente narrativos para a disciplina de História e se apropriam de conceitos e conhecimentos históricos importantes para o vestibular e não para a formação do pensamento histórico, pois, quando um aluno diz: "O livro nos dá informações importantes para o nosso cotidiano, como por exemplo, o surgimento de nosso país, a nossa colonização", ele está simplesmente considerando a História como uma disciplina que dialoga somente com o passado.

Porém, ao analisar o Manual do Professor (MP) do livro didático da RSE, os autores destacam:

Trabalhar com a disciplina de História em sala de aula significa, portanto, colaborar com os alunos para que percebam as marcas do passado em seu cotidiano, demonstrando como o vivido, o aqui e agora, define a leitura do passado e os rumos do próprio presente. Essa atitude implica viabilizar outra relação de conhecimento em sala de aula (ROTA, MACHADO, 2009, p. 40).

Mas, como entender as distorções entre o que os alunos relatam sobre o livro didático e a importância da História com a proposta do Ensino de História dos autores do livro didático?

Nessa direção, Chartier (2001) diz que os leitores participam da produção do sentido de um texto conforme sua posição social, seu contexto cultural, seus valores e seus interesses. Assim, esses também são modificados pelos sentidos impressos no texto pelo autor e pelo editor. Enfim, não há uma relação específica entre texto e o autor, e o autor e leitor. Nem o texto e seu impresso afetam absolutamente o leitor, moldando, por completo, sua visão de mundo e prática social; nem é o leitor que cria sozinho o sentido do texto. Há uma troca de sentidos entre autor-texto/editor-impresso/leitor, inserida em um contexto sócio histórico. Chartier (2001, p. 13) destaca que, 
contra uma visão simplista que supõe a servidão dos leitores quanto às mensagens inculcadas, lembra-se que a recepção é criação, e o consumo, produção. No entanto, contra a perspectiva inversa que postula a absoluta liberdade dos indivíduos e a força de uma imaginação sem limites, lembra-se que toda criação, toda apropriação, está encerrada nas condições de possibilidade historicamente variáveis e socialmente desiguais. Desta dupla evidência $[\ldots]$, estabelece-se o paradoxal entrecruzamento de restrições transgredidas e de liberdades restringidas.

Também se pode remeter ao que Le Goff (2003) critica no seu texto "O singular e o universal: generalizações e singularidades da história", ao questionar os desafios/horizontes da História diante da singularidade do fato histórico. É importante enfatizar que o autor utiliza o termo singularidade histórica na compreensão de que a história só acontecerá uma vez. ${ }^{5}$ Para o autor:

A contradição mais flagrante da história é sem dúvida o fato do seu objeto ser singular, um acontecimento, uma série de acontecimentos, de personagens que só existem uma vez, enquanto seu objetivo, como o de todas as ciências, é atingir o universal, o geral, o regular (LE GOFF, 2003, p. 34).

Desse modo, ao analisar os relatos dos alunos sobre a importância de compreender o passado, percebe-se que, para alguns deles, o professor de História igualmente representa o passado e, consequentemente, é representado como um narrador de acontecimentos, ou ainda, um narrador de grandes fatos e personagens heroicos essenciais para alguns momentos na sua vida, como por exemplo, o vestibular e a vida profissional.

Le Goff (2003) destaca que em consequência do reconhecimento da singularidade do fato histórico, pode-se ressaltar três características da História. Primeiramente, o autor cita a primazia do acontecimento. Nessa concepção, a reconstrução do fato histórico do passado consiste em aplicar aos documentos métodos que possam extrair informações possíveis de serem comprovadas. Porém, como mesmo destaca Le Goff ( 2003, p. 34), esse método "confunde acontecimento e fato histórico, e sabemos hoje que o fim da história não é estabelecer estes dados falsadamente 'reais' batizados de acontecimentos ou fatos históricos". Ainda, analisando outros relatos nessa mesma perspectiva de

\footnotetext{
5 Nesse momento do texto, Le Goff se refere à visão tradicional da História, inclusive cita Aristóteles por este ter afastado a história do mundo das ciências porque ela se ocupa do particular, que não é um objeto das ciências (LE GOFF, 2003, p. 34).
} 
representação do livro didático, como fonte de conhecimentos sobre o passado, outro aluno afirma:

Pois é muito importante para nós termos um total conhecimento do passado, claro que não vamos ter total conhecimento, mas ir buscando cada vez mais, para sabermos diversas coisas, como por exemplo, as histórias do nosso país e de outros países, o motivo de alguns acontecimentos, e até mesmo acontecimentos que ficaram marcados, e assim vai. (Resposta do aluno, 2010).

É importante enfatizar que, na visão desses alunos, a História é uma disciplina que ensina/transmite conhecimentos de grandes atos e heróis, como o processo de colonização e, consequentemente, eles percebem o livro didático como auxílio nesse processo de transmissão dos acontecimentos do passado. Apesar de o Ensino de História, de acordo com as novas correntes historiográficas ${ }^{6}$, apresentar novas perspectivas com base em vários olhares, alguns alunos, uma parcela considerável deles, ainda não compreende a disciplina como integrante do processo de formação do pensamento histórico, mas sim, como algo a ser aprendido e repassado, sem relação com o seu cotidiano. Ou seja, compactuam com uma visão unilateral dos fatos históricos.

A segunda consequência que Le Goff (2003, p. 34) destaca em relação à limitação da História ao singular "consiste em privilegiar o papel dos indivíduos e, em especial, dos grandes homens". Para o autor, essa concepção, infelizmente, continua a ser espalhada por vulgarizadores pela mídia, a começar pelos editores. Esses grandes homens, destaca o autor, não se referem ao gênero biográfico, que é um gênero da História e produziu grandes obras, mas se referem aos grandes homens de forma individual, de exaltação a grandes atos, inferiorizando os demais participantes do fato histórico de forma singular. Essa forma de pensar a História aparece nos relatos dos alunos:

Estabeleço esta relação analisando as formas de governo, pois através do livro tenho como observar como foi evoluindo até os dias de hoje. Por exemplo: como era no início, quando o Brasil se tornou república, como era governado daquela forma e como é hoje a república Federativa do Brasil. (Resposta do aluno, 2010)

\footnotetext{
${ }^{6}$ Refere-se aqui à Nova História Cultural que ganha espaço após a década de 1980 com uma nova concepção de entender a História por intermédio de outras fontes e perspectivas.
} 
Pelo conhecimento de "grandes acontecimentos" históricos, o aluno ainda percebe a História como uma narração linear e progressiva, características da História positivista. Apesar do enfoque dos autores do livro didático da RSE ao propor que os alunos "se apropriem e utilizem com desenvoltura as noções e os conceitos necessários à análise, cada vez mais consciente e autônoma, do presente e do passado" (ROTA, MACHADO, 2006, p. 41), para muitos alunos, isso ainda não faz parte do seu pensamento.

Tanto o livro didático quanto os professores entrevistados e os autores do livro ensaiam abordagens próximas às novas tendências do ensino de História, mas enfrentando forte viés da História tradicional, que representa de forma harmônica e valoriza os "grandes" acontecimentos históricos sob um ponto de vista valoroso de "grandes" personagens heroicos.

Por fim, Le Goff (2003) destaca que a terceira consequência abusiva do papel singular da História consiste em uma narração, a um conto. No relato de um dos alunos, sobre a importância do livro didático de História, fica evidenciada a concepção dessa narrativa histórica quando ele destaca: "Sim, pois vai ser por meio dele que vou conseguir explicar um pouco mais da história para as pessoas que não tiveram acesso a história, que não conhecem o que ocorreu no passado", ou ainda outro depoimento em que o aluno destaca, "Porque eu vou poder discutir 'lá fora'... poder entender muitas coisas com a base do meu conhecimento na história do ser humano 'do passado"'. Nessas falas, observa-se que a concepção de História e os usos do livro didático na disciplina é uma narrativa de acontecimentos passados que eles podem ser transmitidos a outras pessoas "que não tiveram acesso a história".

Para esses alunos, a História pode ser reduzida simplesmente a um conto, a uma história que deve ser contada aos demais por meio do professor ou pelo aluno. Essa narrativa histórica, tal como entendida pelos alunos, é uma narrativa tradicional, nos moldes da História do século XIX e início do século XX de viés positivista. A História, até então, tinha o objetivo de criar a identidade e a coesão nacional, baseava-se em uma concepção de tempo linear, homogêneo e evolutivo, construindo a ideia de que o progresso da nação deve-se aos feitos político-institucionais dos "grandes homens" da elite, ensinada como uma 
verdade indiscutível resgatada dos documentos escritos e oficiais, que deveria ser transmitida pelos professores e absorvida passivamente pelos alunos.

Le Goff (2003, p. 35-36) é enfático ao afirmar que "toda a concepção da história que a identifica com o conto afigurasse-me, hoje, inaceitável. [...] 0 conto não passa de uma fase preliminar, mesmo tendo exigido um longo trabalho prévio por parte do historiador". Nesse sentido, entender a História hoje como um conto, como uma simples narrativa história objetiva, ou um acontecimento estático do passado pelo passado, deixa a desejar.

Diante dessas inquietações, Le Goff (2003, p. 43) destaca que

a história, a medida que se constitui como corpo de disciplina científica e escolar, deve encarnar-se em categorias que, pragmaticamente, a fracionam. Estas categorias dependem da própria evolução histórica: a primeira parte do século XX viu nascer a história econômica e social, a segunda, a história das mentalidades. [..] Por isso, a aspiração dos historiadores à totalidade histórica pode e deve adquirir formas diferentes que, também elas, evoluem com o tempo.

$\mathrm{E}$, o autor conclui dizendo que " não há história imóvel e que a história também não é a pura mudança, mas sim o estado das mudanças significativas".(LE GOFF, 2003, p. 47).

Diante dos relatos, um questionamento é constante: como o aluno pode estabelecer uma relação entre a escrita histórica do livro didático e a sua importância para a vida fora do contexto escolar? Segundo Rüsen (2010, p. 117),

ao se dirigir aos alunos, não se deveria esquecer que a experiência histórica tem um potencial próprio de encantamento que se pode aproveitar como oportunidade de aprendizagem. O espanto e a diferença do passado podem ser apresentados de uma maneira que se acredita ser interessante e curiosa (2010, p. 117).

O autor ainda destaca que

um meio provado para estabelecer uma boa relação com o aluno é dirigir-se a ele explicitamente. Desse modo, pode-se justificar a seleção do tema, pode-se explicar a perspectiva escolhida para a interpretação e, se se faz o mesmo quando se trata o conteúdo, então os alunos o levam a sério quando devem fazê-lo e a referencia do aluno perde a odiosa conotação de uma mera tática didática que, em lugar de reconhecer nos alunos a necessidade de 
orientação histórica realmente própria e inclusive 'muito individual', somente os obriga a acumular conhecimentos politicamente e cientificamente autorizados (RÜSEN, 2010, p. 117).

Levando-se em conta a argumentação de Rüsen e as falas dos alunos em relação ao livro didático e à importância da disciplina de História, remete-se a trechos dos três volumes do livro didático na abertura da Unidade 1 de cada um deles. Assim inicia a apresentação do Volume 1: "Ao ler os capítulos 1 e 2, você notará algumas referências a autores e pesquisadores, entre eles historiadores e sociólogos" (ROTA, MACHADO, 2009, p. 10). O Volume 2 assim inicia: "Nesta primeira unidade do volume 02, iremos estudar as transformações e permanências que marcaram o mundo da produção entre os séculos XI e XIX e ajudaram a formar o mundo que conhecemos" (GRANGEIRO, MACHADO, 2005, p. 10) e no Volume 3 assim está descrito: "Atualmente ouve-se muito falar em nações e estados nacionais, principalmente quando o assunto é globalização" (GRANGEIRO, MACHADO, 2006, p. 10, grifo meu).

O que se pretende destacar mediante esses trechos é que o Volume 1 aqui citado já está revisado e atualizado, e os Volumes 2 e 03 não. A aproximação dos autores com os alunos é mais visível no Volume 1, a utilização da palavra você remete a uma aproximação entre os autores e os alunos que utilizam a coleção, relação que não foi percebida nos volumes 2 e 3 utilizados pelos alunos envolvidos pela pesquisa ${ }^{7}$. Um relato mostra a insatisfação do aluno em relação ao livro didático e à escrita do conhecimento histórico:

O livro de História da RSE é complicado para se entender. Não estimula um aluno que não adora a disciplina a querer saber como as coisas funcionaram no passado. Os exercícios propostos não são bons desestimulando grande parcela dos alunos a fazerem. $\mathrm{Na}$ maioria das vezes, grande parte dos alunos copiam do outro ao invés de realizar a tarefa, por que o livro é chato. (Resposto do aluno, 2010).

Nessa perspectiva, o Professor $\mathrm{II}^{8} \mathrm{diz}$ :

Acredito que ainda encontramos muito da velha história de 'entender o passado' sem ligação com o presente. Os livros tentam

\footnotetext{
7 Grifos da autora deste trabalho.

${ }^{8}$ Os professores entrevistados são identificados como Professor I, Professor II, Professor III e Professor IV, não obedecendo necessariamente à respectiva ordem das escolas citadas a fim de manter o anonimato.
} 
traçar novos olhares sobre a História. Contudo, muitas vezes a maneira como tentam relacionar os conteúdos é deveras forçosa. Analisar a vida do jovem romano ou grego pode parecer mais fácil para historiadores, mas para aqueles que têm um primeiro contato com o assunto e não sabem sequer o básico é muito difícil. (Professor II, 2010).

O Professor II refere-se à Unidade 2 do Volume 1 cujo tema é "A invenção da cidadania". Contudo, o que é importante destacar aqui é que durante a observação da aplicação do questionário na escola na qual o professor trabalha, ficou evidente, na postura e comentários dos alunos, que o professor não utiliza o livro didático; inclusive, no momento da explicação e conversa anterior à aplicação das perguntas, alguns risos entre os alunos foram percebidos como forma de demonstrar o "enfrentamento" dos alunos e professores com o livro didático. Dentre os professores envolvidos na pesquisa, o Professor II é o mais jovem. $^{9}$

Nessa mesma escola, é interessante analisar o gráfico das respostas dos alunos do Professor II:

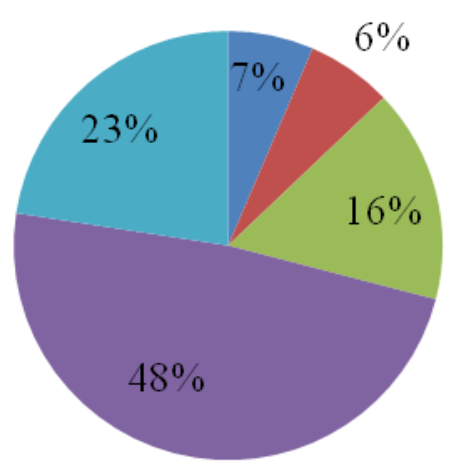

- Conhecer o seu passado e entender o seu presente.

- Preparar-se para a aula

- Formar uma opinião crítica a respeito de determinado assunto

Gráfico 1 - "Você lê o livro didático de História para:". Fonte: Organizado pela autora.

Na escola do Professor II, 71\% dos alunos leem o livro para estudar para a prova ou simplesmente não o leem. Destaca-se que é a escola com o maior índice de desinteresse pelo livro didático. Também são os alunos do Professor II

\footnotetext{
${ }^{9}$ Coloca-se essa informação a respeito do Professor II por considerar que os professores mais jovens e com formação mais recente muitas vezes possuem uma resistência ao uso do livro didático devido a críticas aos livros do século XIX e início do século XX, heranças culturais ainda impregnadas na cultura e no imaginário dos professores.
} 
que demonstraram maior desinteresse pelo livro, atribuindo como justificativa a "opinião" dos autores em excesso na escrita do texto do livro. Assim argumentaram: "Pois a autora, em muitas vezes, baseia-se em sua opinião própria e deixa de lado os conteúdos com visão para uma sala de aula"; "Conteúdos da disciplina sim. No entanto, não gosto das opiniões expressas no livro. Então não absorvo o conteúdo através dele" e "O livro apresenta muita opinião da autora e o que eu preciso é de conteúdo". Foi a única escola que se referiu aos autores de forma direta e negativa, provavelmente, por influência do professor que, segundo os alunos, não gosta do livro: "Porque segundo nosso professor o livro não é interessante. Portanto, não utilizamos com frequência".

Nessa mesma perspectiva de análise das apropriações do livro didático pelos professores e alunos, numa conversa informal com o Professor III, ele destaca que a utilização do livro em sala de aula é um tanto limitada em razão do excesso de teorização na escrita dos conteúdos do livro. Para o Professor III, os autores exageram na abordagem dos conteúdos e não levam em consideração as limitações do cotidiano escolar, como, por exemplo, a quantidade de horas/aula semanais e as especificidades do processo de ensino e aprendizagem que varia de aluno para aluno ou de escola para escola. Para entender melhor a posição do Professor III, destaca-se aqui um trecho da sua fala:

Desde o início fui entusiasta dos livros da Rede por acreditar que eles contêm aquilo que de mais atual se discute em torno do ensino de História. Propõe discussões temáticas, consegue, em alguns momentos, quebrar com a linearidade e incorpora discussões bastante atuais, como o livro do Segundo Ano, no capítulo que fala da terra no Brasil. Essa forma é clara para mim, como professora que tenho todo um arcabouço teórico para pensar a história. Para os alunos, o livro se torna pesado (no sentido literal e figurativo) e com sua compreensão dificultada. (Professor III, 2010).

Durante a visita à escola do Professor III, que possui a maior quantidade de alunos, 63 alunos do terceiro ano do ensino médio, alguns alunos teceram comentários negativos sobre o livro, assim como uma postura de certo descaso com a disciplina de História.

Essa postura pode ser observada nas respostas à pergunta sobre a leitura do livro didático, pois, foi a escola com o segundo maior índice de desvalorização da leitura do livro didático. 


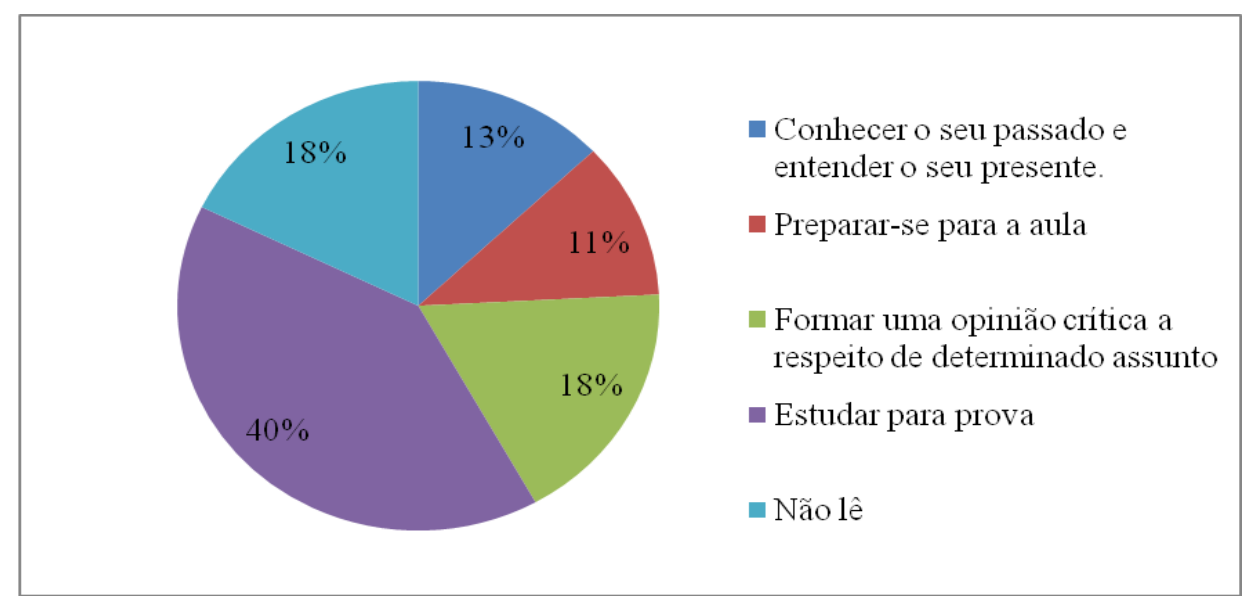

Gráfico 2- "Você lê o livro didático de História para:". Respostas dos alunos do Professor III. Fonte: Organizado pela autora.

Na escola do Professor III, 58\% dos alunos representam o livro didático como um apoio para provas ou simplesmente não o lê. Portanto, mais uma vez foi possível perceber como a apropriação docente do livro didático não segue a ortodoxia do texto escrito e prescrito pelos autores e equipe pedagógica da Rede. Ou seja, os sentidos atribuídos pelos alunos ao livro utilizado consideram o saber intelectual, cognitivo, não relacionando com a sua formação cidadão fora do contexto escolar.

Por conseguinte, as prescrições contidas tanto no MP quanto no livro do aluno, são escolhas dos autores para auxiliar a prática pedagógica e para a aprendizagem do conhecimento histórico. No entanto, os conteúdos a serem ensinados e a apropriação de conceitos que dão sentidos à vida prática do aluno só se efetivam quando ganham forma em práticas concretas dos professores junto aos seus alunos. Com base nas visitas às escolas envolvidas, os professores, apesar de terem se baseado no livro didático e no currículo elaborado pelos autores da RSE para direcionarem e organizarem suas aulas, desencadeiam a utilização de outros recursos além do livro didático, como pesquisas em outros livros didáticos, ou apostilas e em recursos tecnológicos, como a internet.

Enfim, os alunos indagados, a despeito de fazerem parte da geração do novo movimento da História Cultural, do novo olhar para a História, é visível a permanência das apropriações de conceitos tradicionais e as representações do 
livro didático como um simples mecanismo de leitura de passado, sem relação com a vida fora da escola.

A proposta dos autores do livro didático é formar cidadãos que participem da "construção do conhecimento histórico como opção interpretativa que os seres humanos fazem de suas experiências, visando à compreensão das práticas coletivas em sua dinâmica de transformação ou continuidade" (ROTA, MACHADO, 2009 , p. 41). Contudo, o olhar tradicional para os fatos históricos e para o ensino de História como uma disciplina que trata isoladamente o passado, sem conexão com o cotidiano, ainda permanece nas representações dos alunos da terceira série do ensino médio da RSE.

Assim um dos alunos relata sobre a importância da História para a sua vida: "São importantes porque permitem estabelecer relações entre o passado histórico e o presente podendo assim entender fatos que ocorrem na atualidade, bem como a evolução nos modos de vida, na economia, na política e na religião". A partir dessa perspectiva do aluno e de demais relatos, questiona-se, primeiramente, o conceito do que é o presente. Bloch (2001, p. 60) assim destaca a esse respeito:

No infinito da duração, um ponto minúsculo e que foge
incessantemente; um instante que mal nasce morre. Mal falei, mal
agi e minhas palavras e meus atos naufragam no reino de
Memória. São palavras, ao mesmo tempo banais e profundas, do
jovem Goethe: não existe presente, apenas um devir, nichts
gegenwartig, alles voubergehend. Condenada a uma eterna
transfiguração, uma pretensa ciência do presente se
metamorfosearia, a cada momento de seu ser, em ciência do
passado.

Portanto, em poucas palavras, Bloch (2001, p. 60) define o presente como "passado recente". Porém, ao analisar os depoimentos, percebe-se que é muito nítido para os alunos a concepção de entendimento do passado como meio de compreender o presente, mas não como um "passado recente", e sim, um passado distante, estático e numa perspectiva de causa e consequência linear.

Rüsen (2010) destaca as competências a serem alcançadas com o ensino de História tomando por fundamento o livro didático. Para o autor, que considera o livro de História o guia mais importante da aula de História, é importante que o livro permita ao aluno, por intermédio do relato histórico, a formação da 
consciência histórica. ${ }^{10}$ Rüsen (2010) acredita que um livro didático, para ser considerado ideal para conseguir a orientação da experiência da vida por meio da memória histórica, deve atingir três competências históricas: a experiência, a teoria e a prática ${ }^{11}$.

A aprendizagem da história é um processo de desenvolvimento da consciência histórica no qual se deve adquirir competências da memória histórica. As competências que permitem efetuar uma idéia de organização cronológica que, como uma coerência interna entre passado, presente e futuro, permitirá organizar a própria experiência de vida, são as mesmas competências de que necessitam para poder receber e também para produzir histórias (RÜSEN, 2010, p. 113).

Rüsen (2010, p. 114-115) destaca que, para atingir essas competências, é importante que o livro didático possa cumprir sua função de guia do processo de aprendizagem histórica. Todavia, nos relatos dos professores, eles reconhecem a tentativa dos autores de considerar a categoria tempo como fonte de análise histórica procurando aproximar a experiência, a teoria e a prática ${ }^{12}$. Ou seja, uma integração entre a percepção, a interpretação e a orientação. Porém, também se evidencia nas suas falas, principalmente, nos relatos dos Professores II, III e IV, a importância do professor nesse processo - talvez o considerem mais importante até que a produção da escrita no livro didático. Ao serem questionados sobre se o livro didático orienta o professor a considerar seu espaço/tempo como fonte de análise histórica, assim os professores se manifestaram:

Professor I- Em cada capítulo ele compara acontecimentos em outros lugares ao mesmo tempo. O tempo deve ser estudado para se observar as rupturas e permanências.

10 Relato para Rüsen, não no sentido de entender uma mera descrição, mas no sentido de uma forma de saber e de entendimento antropologicamente universais e fundamentais (RÜSEN, 2010, p. 112).

${ }^{11}$ A competência embasada na experiência consiste em saber perceber o passado como tal, isto é, em seu distanciamento e diferenciação do presente, em vê-lo a partir do horizonte de experiências do presente como um conjunto de ruínas e tradição. A competência teórica (ou interpretativa) consiste em saber interpretar o que temos percebido com passado em relação e conexão de significado e de sentido com a realidade e a competência de orientação consiste em admitir e integrar a "História" como construção de sentido com o conteúdo de experiências do passado, no marco de orientação cultural da própria experiência de vida.

12 Nos relatos dos professores, não foram citadas nessa perspectiva de Rüsen, de experiência, teoria e prática, porém, entende-se nas falas que as três competências são perceptíveis na coleção didática produzida e adotada pela Rede. 
Professor II- Acredito que ainda encontramos muito da velha história de "entender o passado" sem ligação com o presente. Os livros tentam traçar novos olhares sobre a História. Contudo, muitas vezes a maneira como tentam relacionar os conteúdos é deveras forçosa. [...].

Professor III- Creio que essa percepção está bastante relacionada com a formação que o próprio professor teve. O livro sugere isso em algumas atividades onde pede que os alunos analisem seu cotidiano, suas relações pessoais. O livro acaba por ser uma ferramenta de reflexão para as aulas, mas a utilização do mesmo como inspiração para o trabalho de autoria, para pensar seu tempo...poderia talvez ser mais desenvolvida... os textos poderiam dar espaço, por exemplo, ao desenvolvimento de pesquisas... mas é claro que isso demandaria uma nova formatação do material.

Professor IV-O livro abre possibilidade para o professor trabalhar os conceitos de espaço/tempo, porém cabe ao professor condicionar as análises realizadas em sala para fazer com que os alunos percebam a lógica por detrás dos processos históricos com seus conceitos de espaço/tempo. (Professores I, II, III e IV, 2010).

Os relatos dos quatro professores envolvidos na pesquisa, principalmente dos Professores II, III e IV, apontam para a importância da formação e da prática do professor que atua em sala de aula; porém, o Professor I manteve-se neutro utilizando como referência para responder ao seu questionário o MP.

De acordo com Rüsen (2010, p. 116), "a questão sobre se certos conteúdos históricos são adequados ou não para um livro didático depende do grau em que estes contribuam para a compreensão do presente e as oportunidades vitais das crianças e jovens". Para o autor o livro didático somente é útil se for possível trabalhar com ele, em sala de aula; caso o livro contenha exclusivamente uma exposição da história, será inadequado para estimular as competências de percepção, interpretação e orientação.

Assim, a escrita dos conteúdos históricos torna-se determinante no processo de encantamento do aluno e, consequentemente, à formação do pensamento histórico. Diante das falas dos professores, pode-se inferir que o livro didático de História da RSE possui um conteúdo histórico excessivamente teórico e que necessita constantemente da aproximação e intermediação do professor para o aluno conseguir fazer as conexões e entendimentos que prescreve e julga necessários. 


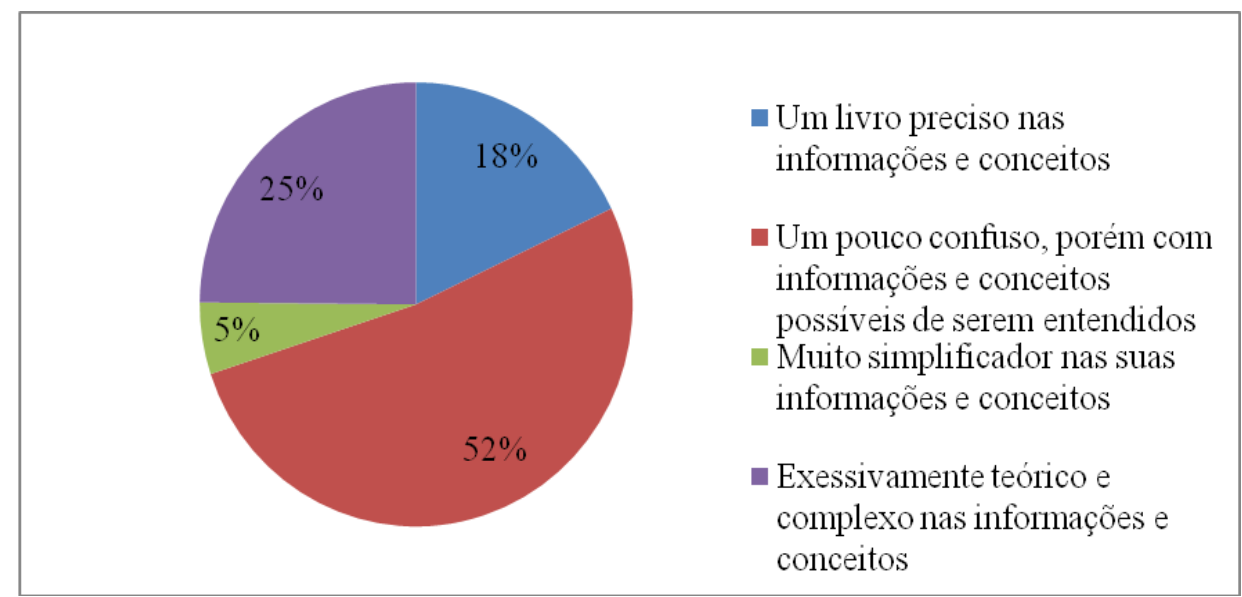

Gráfico 3 -" Em relação à escrita do conteúdo no livro didático de História da Rede, você considera:".

Fonte: Organizado pela autora.

Ao se considerar os argumentos de Rüsen (2001) para um bom livro didático sobre a escrita da História, pode-se dizer que somente $18 \%$ dos alunos pesquisados conseguem encontrar o encantamento e o espanto a qual o autor destaca para um livro didático ser considerado bom. ${ }^{13}$ Os professores apresentaram opiniões semelhantes ao se referir ao excesso de teorização do livro, assim como, 25\% dos alunos entrevistados.

Para exemplificar a opinião dos alunos, utiliza-se o Volume 3. O Volume 3 possui 336 páginas divididos em nove capítulos. Ou seja, o conteúdo histórico, que deveria ser prazeroso para os alunos, torna-se um desafio semanal para o professor terminar o livro, pois, a equipe pedagógica da Rede, a direção e coordenação da escola impõem como regra o término do livro didático, inclusive a execução das atividades metodológicas. Porém, isso é dificultado pelo número de aulas semanais que variam de uma a três aulas, dependendo da escola.

Em relação a essa discussão, destacam-se aqui os relatos dos alunos sobre a importância da disciplina de História a partir do uso do livro didático:

1- Pois vem através desse conhecimento que posso entender por exemplo: de onde vem a minha cidade, como se formou essa cultura, etc.

2- Podemos entender várias situações cotidianas que muitas vezes acontecem por consequência de fatos ocorridos no passado.

${ }^{13}$ Expressões utilizadas por Rüsen para ajudar na aprendizagem histórica (2010, p. 117). 
3- Associando a relação do que acontece hoje como consequência do que houve no passado.

4- Quando relacionamos as culturas, a política, tudo em geral, vemos que o que acontece hoje é devido ao que ocorreu no passado, por exemplo: a desigualdade social, discriminação racial...

5- O livro didático nos fornece muitos conhecimentos e possibilita que consigamos entender um pouco mais do passado, pois foi lá que as coisas começaram a acontecer e traz o mundo como é hoje, portanto é um conhecimento muito bom e todos deveriam ter.

6- Conhecimentos do nosso país, o passado dele desde a época do "descobrimento", Independência, República. Ainda mais em ano de eleição, para votar consciente e não cometer os mesmos erros do passado.

7- Pois, é a partir do livro didático que a compreensão do assunto e melhor e com ela posso analisar e comparar o que aconteceu no passado com o que corre atualmente.

8- Sim, o livro não traz apenas conteúdos passado, mas também atualidades, fazendo comparações de antigamente e hoje.

9- Sim, pois nos faz pensar sobre ações tomadas no passado e que podem ser evitadas. (Respostas dos alunos, 2010).

Nesses relatos, percebe-se que a escrita do conteúdo histórico está relacionada às apropriações que os alunos fazem da disciplina de História. Nessa perspectiva, Bloch (2001, p. 65) destaca que "a incompreensão do presente nasce fatalmente da ignorância do passado. Mas talvez não seja menos vão esgotar-se em compreender o passado se nada se sabe do presente". Quer dizer, a História deve ser compreendida a partir do presente, da sociedade hoje, dos desafios contemporâneos para daí sim chegar ao entendimento do passado. No entanto, os alunos representam o conhecimento histórico como forma de conhecer o passado para compreender o presente, novamente numa perspectiva linear de causa e consequência e uma perspectiva de que a partir dos acontecimentos passado, vai-se determinando o presente. Utilizando aqui os argumentos de Bloch (2001), nota-se que o processo de construção histórica ainda não é sentido, vivido por parte dos alunos.

O autor ainda destaca que, "além de tudo, a educação da sensibilidade histórica nem sempre está sozinha em questão. Ocorre de, em uma linha dada, o conhecimento do presente ser diretamente ainda mais importante para a compreensão do passado". Se a História é "a ciência dos homens, no tempo" (BLOCH, 2001, p. 55), cabe compreendê-la pelo presente, para dar sentido e significados ao tempo presente e não somente ao passado. 
Ao afirmar: "pois, é a partir do livro didático que a compreensão do assunto é melhor e com ela posso analisar e comparar o que aconteceu no passado com o que ocorre atualmente", constata-se que o aluno dá importância à disciplina de História no momento em que ele pretende entender o presente mediante comparações com o passado, evidenciando uma concepção de História unidimensional. Considera-se aqui as afirmações de Le Goff (2003, p. 48), ao afirmar que "a história não deve preocupar apenas com a produção histórica profissional, mas com todo o conjunto de fenômenos que constituem a cultura histórica, ou melhor, a mentalidade histórica de uma época".

No relato do aluno, a disciplina de História é uma narrativa do passado, um conhecimento que deve ser conhecido para estabelecer relações/comparações com o presente e não está considerando a mentalidade histórica de diferentes épocas como propõem Le Goff (2003). Compreender a mentalidade histórica de uma época é entender os diferentes olhares de um acontecimento e assim construir - ou reconstruir - uma história que considere as especificidades culturais de um povo, de uma nação ou até mesmo da história de vida do aluno.

Hobsbawm (1998, p. 24) do mesmo modo ajuda a compreender a História numa perspectiva de relação entre o presente e passado.

A crença de que o presente deva reproduzir o passado normalmente implica um ritmo positivamente lento de mudança histórica, pois, caso contrário, não seria, nem pareceria realista, exceto à custa de imenso esforço social e do tipo de isolamento que pode ocorrer na sociedade ou em comunidades.

O autor ainda argumenta que,

quando a mudança social acelera ou transforma para além de um ponto, o passado deve cessar de ser o padrão do presente, e pode, no máximo, tornar-se modelo para o mesmo. 'devemos voltas aos caminhos de nossos antepassados' quando já não trilhamos automaticamente, ou quando não é provável que o façamos. Isso implica uma transformação fundamental do próprio passado. Ele agora se torna, e deve se tornar, uma máscara para inovação, pois já não expressa a repetição daquilo que ocorreu antes, mas ações que são, por definição, diferentes das anteriores. Mesmo quando se tenta realmente retroceder o relógio, isso não restabelece de fato os velhos tempos, mas meramente certas partes do sistema formal do passado consciente, que agora são funcionalmente diferentes (HOBSBAWM 1998, p. 25). 
Portanto, conhecer o passado implica uma mudança de entendimento do presente. Mas essa mudança só ocorre quando o passado não é formalizado, estático, pois, como acrescenta Hobsbawm (1998, p. 25), a tentativa de restabelecer um passado perdido não pode ter sucesso completo, exceto em formas triviais como a reconstrução da cultura material e não da complexidade das sociedades que se formaram ao longo dos séculos.

\section{Considerações finais}

A utilização do livro didático e suas apropriações por professores e alunos da Rede evidenciam-se em diferentes formas e objetivos, diferenças estas mais marcantes pelos alunos. Apesar dos autores produzirem suas obras, expressar leituras, posicionamentos pedagógicos e orientações institucionais, eles "selecionam a produzem saberes, habilidades, valores, visões de mundo, símbolos, significados, portanto culturas, de forma a organizá-los para torná-los possíveis de serem ensinados" (LOPES, 2004, p. 111). Porém, embora a proposta pedagógica dos autores propõe uma nova visão de História, uma nova abordagem pedagógica e metodológica da disciplina, muitos alunos ainda não a compreendem como um processo vivo e em constante (re) construção que pode servir como orientação para a sua vida.

Enfim, percebe-se a intrínseca relação entre a compreensão da disciplina de História, do livro didático e a temporalidade histórica. No entanto, destaca-se aqui, como um desafio constante, tanto para os professores de História quanto para os autores dos livros didáticos, atribuir sentidos e significados ao ensino de História, para que, aos poucos, os sentidos sejam reinventados no cotidiano escolar para os alunos que não compreendem a História e suas múltiplas temporalidades.

\section{Referências}

BISEWSKI, O. Práticas de formação continuada de professores: estudo de caso na rede Salesiana de Escolas. 2008. 100 f. Dissertação (Mestrado em Educação 
nas Ciências) - Universidade do Noroeste do Estado do Rio Grande do Sul, Rio Grande do Sul.

BLOCH, M. Apologia da história, ou, O ofício do historiador. Rio de Janeiro: Jorge Zahar. Ed., 2001.

FONSECA, S. G. Didática e prática de ensino de história: Experiências, reflexões e aprendizados. Campinas, SP: Papirus, 2003.

GRANGEIRO, C. D.; MACHADO, R. R. História: ensino médio, 20 ano. Brasília: Cisbrasil - CIB, 2005.

GRANGEIRO, C. D.; MACHADO, R. R. História: ensino médio, 20 ano. Brasília: Cisbrasil - CIB, 2006.

HOBSBAWM, E. Sobre História. Tradução Cid Knipel Moreira. São Paulo:

Companhia das Letras, 1998.

KOSELLECK, R. Futuro Passado: contribuição à semântica dos tempos históricos. Trad. Wilma Patrícia Maas e Carlos Almeida Pereira. Rio de Janeiro: Contraponto, Ed. PUC-Rio, 2006.

LAVILLE, C. A guerra das narrativas: debates e ilusões em tornodo ensino de História. Revista Brasileira de História. São Paulo, v. 19, n. 38, p. 125-138. 1999.

LE GOFF, J. História e memória. Trad. Bernardo Leitão et al. 5. ed. Campinas: Unicamp, 2003.

LOPES, A. C. Políticas curriculares: continuidade ou mudança de rumos? Revista Brasileira de Educação. Rio de Janeiro, n. 26, p. 109-118, maio /jun./jul./ago., 2004.

NADAI, E. O ensino de História e a "pedagogia do cidadão". In: PINSKY, J. O ensino de história e a criação do fato. - ver. E atual. - São Paulo: Contexto, 2009.

CHARTIER, R. Cultura escrita, literatura e história. Trad. Ernani Rosa. Porto Alegre: ARTMED Editora, 2001.

ROTA, P. S. MACHADO, R. R. História: ensino médio, $1^{\circ}$ ano. 2 ed., Brasília: Cisbrasil - CIB, 2009.

RÜSEN, J. Jörn Rüsen e o ensino de história. SCHMIDT, M. A.; BARCA, I.; MARTINS, E. de R. Curitiba: Ed. UFPR, 2010. 